\title{
Approach to the diagnosis and management of suspected exercise-induced bronchoconstriction by primary care physicians James H Hull ${ }^{\dagger 1}$, Peter J Hull ${ }^{\dagger 2}$, Jonathan P Parsons ${ }^{\dagger 3}$, John W Dickinson ${ }^{\dagger 4}$ and Les Ansley*+5
}

\begin{abstract}
Address: ${ }^{1}$ Faculty of Health and Social Care Sciences, Kingston University and St George's Hospital, London, UK, ${ }^{2}$ Abbotsbury Road Primary Care Centre, Weymouth, Dorset, UK, ${ }^{3}$ Division of Pulmonary, Allergy, Critical Care and Sleep Medicine, Ohio State University, Colombus, Ohio, USA, ${ }^{4}$ Carnegie Centre for Performance and Wellbeing, Leeds Metropolitan University, Headingley, Leeds, UK and ${ }^{5}$ School of Psychology \& Sport Sciences, Northumbria University, Newcastle, UK
\end{abstract}

Email: James H Hull - jiminio@doctors.org.uk; Peter J Hull - pete@hull69.plus.com; Jonathan P Parsons - jonathan.parsons@osumc.edu; John W Dickinson - johndicko@yahoo.co.uk; Les Ansley* - les.ansley@northumbria.ac.uk

* Corresponding author †Equal contributors

Published: 15 June 2009

BMC Pulmonary Medicine 2009, 9:29 doi:10.1186/1471-2466-9-29

This article is available from: http://www.biomedcentral.com/I47/-2466/9/29

(C) 2009 Hull et al; licensee BioMed Central Ltd.

This is an Open Access article distributed under the terms of the Creative Commons Attribution License (http://creativecommons.org/licenses/by/2.0), which permits unrestricted use, distribution, and reproduction in any medium, provided the original work is properly cited.
Received: I December 2008

Accepted: 15 June 2009

\begin{abstract}
Background: Exercise-related respiratory symptoms in the diagnosis of exercise-induced bronchoconstriction (EIB) have poor predictive value. The aim of this study was to evaluate how athletes presenting with these symptoms are diagnosed and managed in primary care.

Methods: An electronic survey was distributed to a random selection of family practitioners in England. The survey was designed to assess the frequency with which family practitioners encounter adults with exercise-related respiratory symptoms and how they would approach diagnostic work-up and management. The survey also evaluated awareness of and access to diagnostic tests in this setting and general knowledge of prescribing asthma treatments to competitive athletes.
\end{abstract}

Results: 257 family practitioners completed the online survey. One-third of respondents indicated they encountered individuals with this problem at a frequency of more than one case per month. Over two-thirds of family practitioners chose investigation as an initial management strategy, while one-quarter would initiate treatment based on clinical information alone. PEFR pre- and postexercise was the most commonly selected test for investigation (44\%), followed by resting spirometry pre- and post-bronchodilator (35\%). Short-acting $\beta_{2}$-agonists were the most frequently selected choice of treatment indicated by respondents $(90 \%)$.

Conclusion: Family practitioners encounter individuals with exercise-related respiratory symptoms commonly and although objective testing is often employed in diagnostic work-up, the tests most frequently utilised are not the most accurate for diagnosis of EIB. This diagnostic approach may be dictated by the reported lack of access to more precise testing methods, or may reflect a lack of dissemination or awareness of current evidence. Overall the findings have implications both for the management and hence welfare of athletes presenting with this problem to family practitioners and also for the competitive athletes requiring therapeutic use exemption. 


\section{Background}

Exercise-induced bronchoconstriction (EIB) is highly prevalent in athletes at all levels of competition and its diagnosis and treatment is important to ensure their wellbeing $[1,2]$. Accurate diagnosis is essential to avoid misclassification and inappropriate treatment [3] and in competitive athletes is particularly important given potential implications on performance and strict regulations concerning the use of medications [4].

In January 2009, the World Anti-Doping Agency (WADA) implemented a number of significant changes in their policy for therapeutic use exemption (TUE) [5], the process through which an athlete may be permitted to use an otherwise prohibited substance to treat a medical condition. A key change to the policy concerns the TUE procedure for inhaled $\beta_{2}$-agonists in asthma or EIB.

The change in the TUE policy will address an important aspect of EIB, namely the poor correlation between exercise-related respiratory symptoms and objective evidence of reversible airway narrowing $[6,7]$. It is currently recognized that clinical assessment alone is often insufficient to ensure a secure diagnosis of EIB; symptoms have poor predictive value and there exists a broad differential diagnosis [8]. Thus, the new policy requires submission of objective evidence of airway hyperresponsiveness to support diagnosis and as such has immediate implications for athletes but ultimately ramifications for the physicians overseeing their care.

In the UK, the majority of athletes with exercise-related respiratory symptoms will be assessed and treated in primary care. In the 12 months from $1^{\text {st }}$ August 2007 to $31^{\text {st }}$ July $200864 \%(\mathrm{n}=528)$ of all TUE applications for inhaled $\beta_{2}$-agonists and corticosteroids were completed by family practitioners (personal communication, UK Sport). Of these applications less than $5 \%$ provided supporting evidence of reversible airway limitation, indicating that objective tests may not be commonly utilised in diagnosis. This assumption is in line with the observed practise of family practitioners in the US, where it has been argued that a lack of objective testing in diagnostic work-up may be leading to inaccurate or missed diagnoses [9].

Recent reviews highlight the difficulties faced by family practitioners when evaluating exercise-induced respiratory disorders [10], but problems may also arise because of an insufficient awareness or lack of access to appropriate tests. Currently however, exactly how family practitioners diagnose and manage athletes with suspected EIB remains undefined. We therefore conducted a survey of family practitioners in England designed to evaluate their clinical knowledge and approach to an athlete presenting with exercise-related respiratory symptoms suggestive of EIB.

\section{Methods}

\section{Survey design and population}

An electronic survey was designed to be distributed to family practitioners to explore the following aspects of diagnosis and management of exercise-related respiratory symptoms suggestive of EIB:

1) Frequency of consults of exercise-related respiratory symptoms in adults.

2) Strategies employed in diagnosis and management of a clinical scenario of suspected EIB.

3) Awareness of and access to tests used in diagnosis of EIB.

4) General knowledge of prescribing treatment for EIB in competitive athletes.

Data was collected over a six month period between February and July 2008. Surveys were anonomysed and processed by an independent analysis facility (Surveymonkey.com). The study was approved by the university research ethics committee (SUB_LA_1207) and all respondents were required to indicate informed consent before they were allowed to continue with the survey. Respondents were not compensated for completing the survey. Only fully completed surveys were used in final analysis.

\section{Survey instrument}

The survey consisted of one clinical scenario (see below) and a series of multiple-choice questions. The scenario was based on a clinical presentation of an athlete with exercise-related respiratory symptoms encountered in primary care practice by one of the authors.

A 24-yr-old competitive cyclist consults you complaining of 'difficulty breathing' when exercising. He says symptoms start shortly after starting riding and reports difficulty 'catching his breath'. He also reports hearing occasional wheeze. He has no other medical history and otherwise feels very well. Examination and peak flow are normal. What is your next management step?

- Advise reduction in exercise exposure

- Arrange further testing

- Prescribe treatment 
- Reassure unlikely to be problem - no treatment or testing arranged

- Refer to specialist

In order to simulate 'real-life' clinical practise and hence allow insight into investigation and management choices the questions within the survey had built-in logic steps i.e. successive questions were based on previous answers. This allowed an 'interactive' and hence more representative assessment of how family practitioners would approach the clinical scenario. It also permitted a further evaluation of management choice when respondents were provided with test results indicating no evidence of airway hyperresponsiveness (i.e. not fulfilling criteria to support a diagnosis of EIB) or when presented with a later re-consult with ongoing symptoms. The order in which the possible choices were presented was randomised for each respondent to avoid response bias. The survey did not permit respondents to revise their answers retrospectively.

Face validity was assessed in a pilot survey distributed to a cohort of twenty family practitioners with adjustments made prior to distribution of the final survey.

\section{Survey distribution}

The survey was distributed as an electronic e-mail link, via primary care trusts (PCTs) to their e-mail distribution list of registered family practitioners/primary care practice managers. A random selection of representative PCTs in England were approached and $90 \%$ agreed to distribution. The nature of the distribution method did not allow an evaluation of successful delivery of e-mails and hence a determination of response rate. Furthermore the survey was only granted distribution on a single occasion within each PCT.

\section{Statistical analysis}

Analysis of data is predominantly descriptive. Investigation of the influences of frequency of encounter (high $(\geq$ 11 per year) and low ( $<11$ per year)) and region (north, midlands, south) on responses were assessed using either Fisher's Exact Test $(2 \times 2)$ or Chi-squared Test for Independence. All percentages are rounded to the nearest integer. Significance was accepted at $\mathrm{p}<0.05$.

\section{Results}

\section{Distribution and response rate}

269 family practitioners started the survey and 257 (96\%) completed the survey.

\section{Frequency of consult}

Respondents' answers to the question 'Approximately how many patients a year do you see complaining of respiratory symptoms occurring during dedicated exercise?' are shown in
Figure $1.35 \%$ of respondents indicated that they encountered at a frequency corresponding to at least one case per month. There were no regional differences in the frequency (i.e. high or low) of cases $(\mathrm{p}=0.14)$.

\section{Strategies employed in diagnosis and management of clinical scenario}

The management strategy selected by family practitioners when faced with the clinical scenario is illustrated in Figure 2. The choice of initial management strategy did not relate to frequency of encounter reported in the first question $(\mathrm{p}=0.89)$.

\section{Choice of test}

No respondents selected a bronchoprovocation test as an initial investigation. Choice of the three most commonly selected tests namely: PEFR; spirometry pre and post bronchodilator (spiroBD); and spirometry pre and post exercise (spiroEX), did not relate to consult frequency (p $=0.59)$ or geographical region $(\mathrm{p}=0.45)$.

Respondents indicated they would select "other" investigations in $4 \%$ of cases. These included: a trial of inhaled $\beta_{2}$-agonist during exercise, serial peak flow monitoring, peak flow with reversibility testing and in one case full blood count, chest radiograph, electrocardiogram and echocardiogram. The 'next-step' management strategy selected when respondents were presented with a test result that did not support diagnosis of EIB (e.g. 'there is less than 10\% difference in PEFR before and after exercise') is shown in Figure 3.

\section{Choice of treatment}

$90 \%$ of practitioners chose short-acting $\beta_{2}$-agonists (SABA) as their initial treatment option and $2 \%$ selected

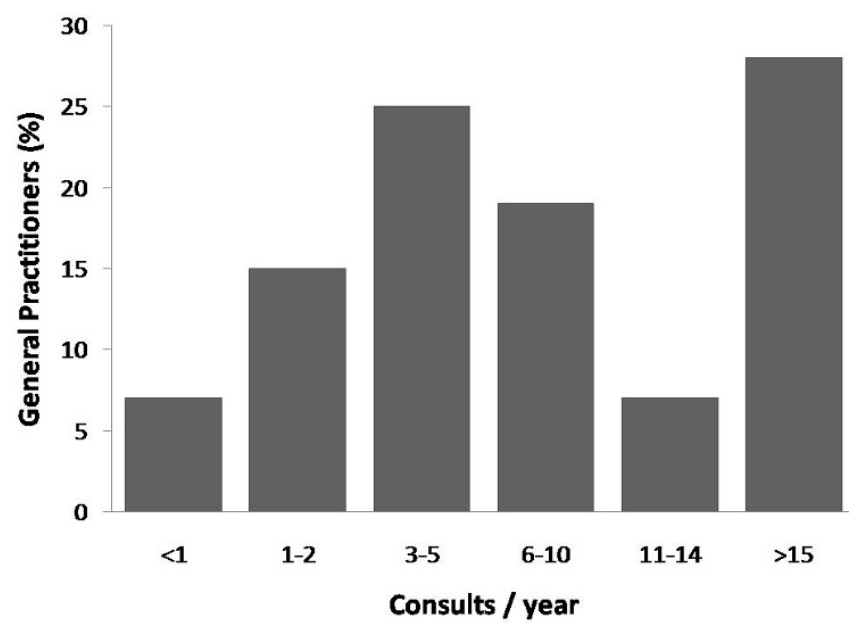

\section{Figure I}

Frequency of consult with exercise-related respiratory symptoms. 


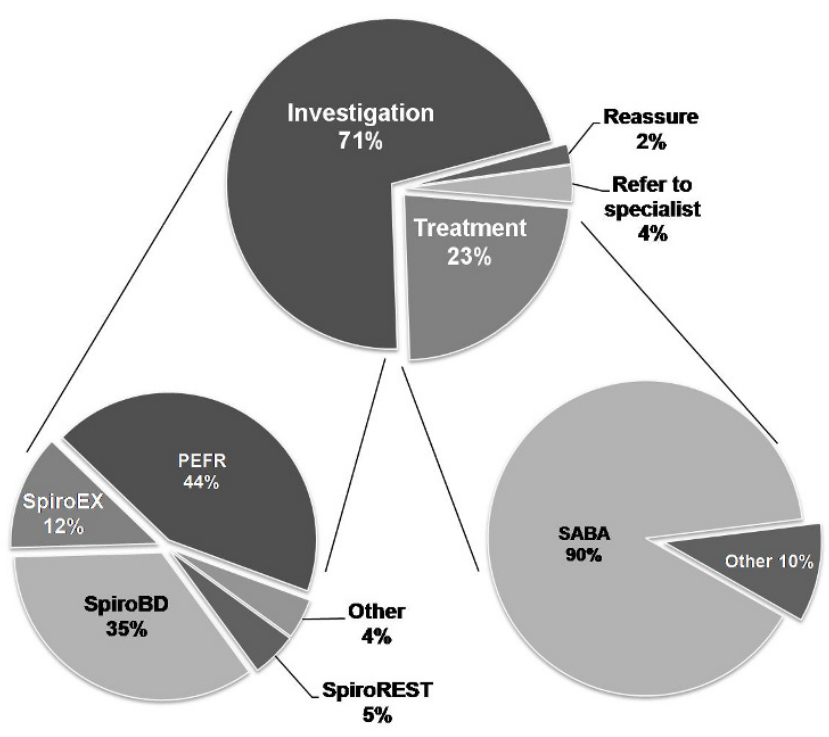

Figure 2

Management strategy of clinical scenario. Definition of abbreviations: SpiroEX = spirometry pre and post exercise; SpiroBD = spirometry pre and post bronchodilator; SpiroREST = spirometry at rest; $\mathbf{P E F R}=$ peak flow pre and post exercise; $\mathbf{S A B A}=$ short-acting $\beta_{2}$-agonist.

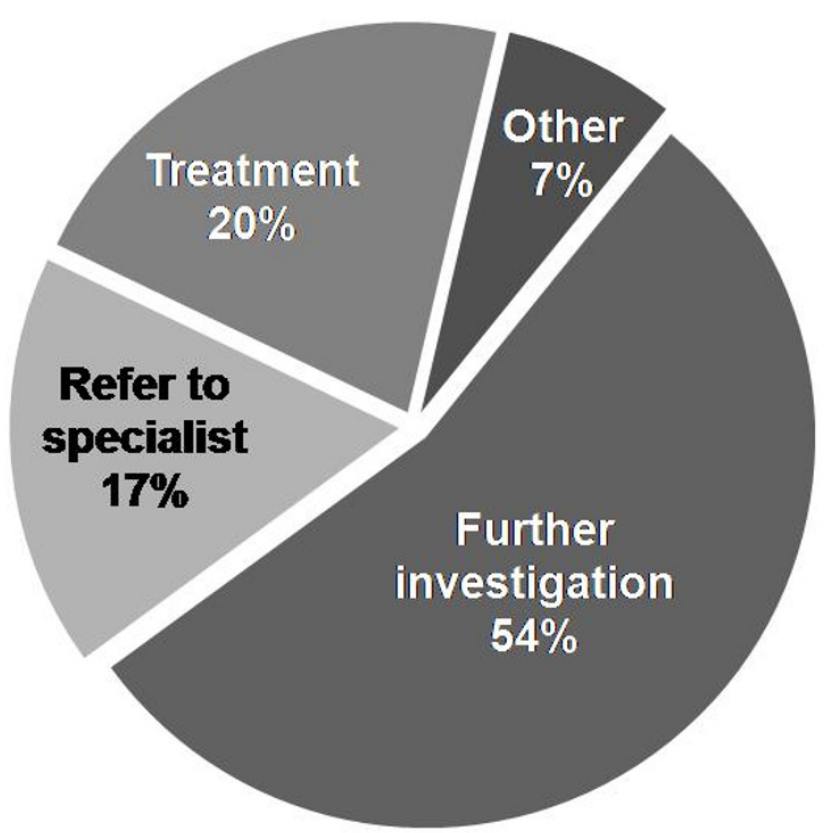

Figure 3

Management strategy following an inconclusive initial test result (i.e. not supportive of EIB). to combine SABA with inhaled corticosteroids (ICS). In $3 \%$ of cases respondents indicated initial treatment with long-acting $\beta_{2}$-agonists (LABA) without ICS if faced with this clinical scenario with $2 \%$ choosing LABA combined with ICS. A further $2 \%$ selected to treat with ICS on its own and $2 \%$ chose leukotriene receptor antagonists. No respondents selected oral corticosteroid, anti-cholinergics, sodium cromoglycate (cromones) or theophyllines (xanthines). Analysis was performed for those who selected empirical treatment as to management strategy at a re-consult two months later - 'The cyclist returns to see you 2 months later complaining of ongoing symptoms and feels that they are limiting his performance. What is your next management step' (Figure 4). The instance of ICS treatment increased from $6 \%$ at initial consult to $75 \%$ at re-consult.

\section{Access to objective tests}

In response to the question, 'To which of the following test(s), used in the diagnosis of exercise-induced bronchoconstriction, do you have access?', $11 \%$ of the family practitioners indicated they have access to laboratory exercise testing while only $4 \%$ have access to eucapnic voluntary hyperpnea $(\mathrm{EVH})$, metacholine or mannitol provocation testing. $85 \%$ of respondents had no access to any bronchoprovocation tests.

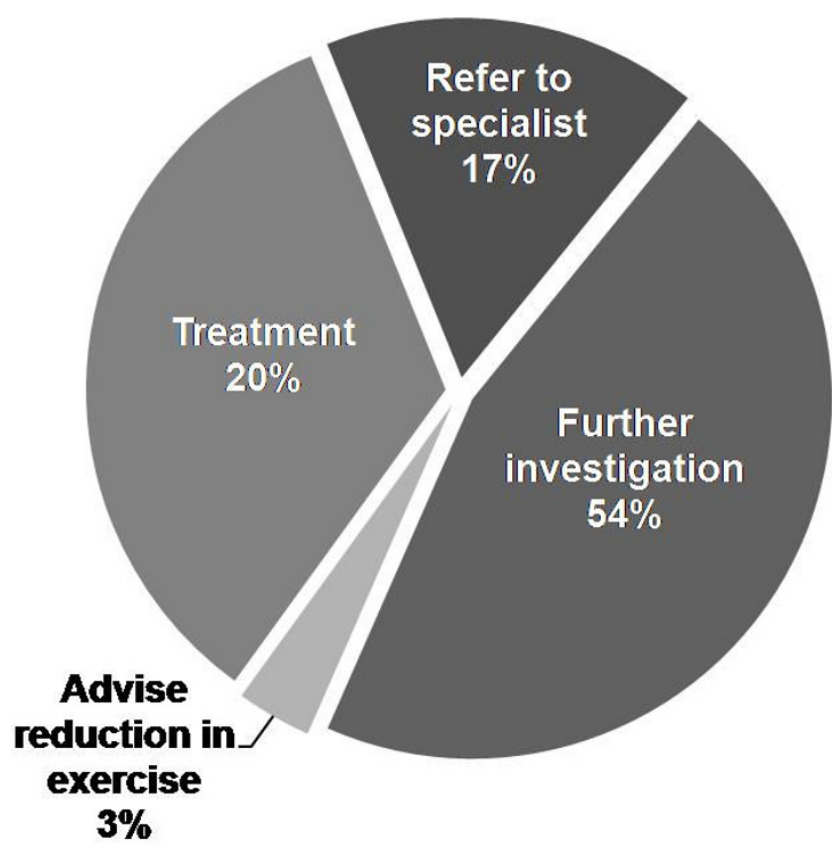

Figure 4

Management strategy at re-consult following initial empirical treatment. 


\section{General knowledge of prescribing treatment for EIB in competitive athletes}

Responses to the question 'which of the following medications is a competitive cyclist permitted to use without notifying their governing body?' are shown in Table $1.8 \%$ of respondents thought that none of the medications were permitted for use without notification while $66 \%$ of respondents felt unsure.

\section{Discussion}

The results from this survey indicate that it is common for family practitioners to encounter individuals with exercise-related respiratory symptoms; with over a third reporting at least one case per month. When faced with such a scenario nearly three quarters of respondents $(71 \%)$ indicated they would select objective testing to diagnose EIB. However the most commonly selected tests, namely exercise PEFR (44\%) and spirometry with bronchodilator (35\%), have been found to have poor diagnostic accuracy for EIB $[11,12]$. In addition, a quarter of family practitioners $(23 \%)$ indicated they would treat empirically based upon clinical features alone. Overall this raises concern that diagnosis of EIB may be inaccurate or indeed missed [6,7] and as such, these findings have implications for the welfare of athletes with this problem. They also have ramifications for competitive athletes given the mandatory requirement for objective evidence in application for inhaled $\beta_{2}$-agonists TUE from Jan 2009; perhaps in particular for those athletes who may apply to renew their TUE on the back of an unsound initial diagnosis.

The International Olympic Committee-Medical Commission (IOC-MC) has recently renewed its consensus guidelines for the diagnosis of EIB in athletes with respiratory symptoms [13]. It is recommended that athletes with abnormal baseline spirometry $\left(\mathrm{FEV}_{1}<80 \%, \mathrm{FEV}_{1} / \mathrm{FVC}<\right.$ 0.7 ) should be investigated initially with a bronchodilator challenge and otherwise with a bronchoprovocation chal-

\section{Table I: Responses to the question 'which of the following medications is a competitive cyclist permitted to use without notifying their governing body?}

\begin{tabular}{lc}
\hline Medication & Responses (\%) \\
\hline Inhaled short-acting $\beta_{2}$-agonists & 20 \\
Inhaled long-acting $\beta_{2}$-agonists & 14 \\
Inhaled corticosteroid & 9 \\
Inhaled corticosteroid and short-acting $\beta_{2}$-agonists & 7 \\
Inhaled corticosteroid and long-acting $\beta_{2}$-agonists & 6 \\
Oral corticosteroid & 1 \\
Leukotriene receptor antagonists & 18 \\
Anticholinergics & 11 \\
Sodium cromoglycate & 18 \\
Theophyllines & 4
\end{tabular}

lenge; the latter being defined as a test with the purpose of evaluating change in airway calibre in response to an airway challenge (e.g. exercise, EVH, methacholine, or mannitol provocation).

This guidance is based on the fact that bronchodilator testing in athletes is unlikely to detect airway reversibility in those with normal resting spirometry [1] and that bronchoprovocation testing has the highest sensitivity and specificity for diagnosis [14]. The IOC-MC guidelines also underline use of $\mathrm{FEV}_{1}$ as a marker of airway narrowing [8] given that use of PEFR may lead to misclassification [11] and as such is no longer recommended in guidelines or accepted by WADA. Please see relevant section in http:// www.100percentme.co.uk for approach and algorithm recommended for UK athletes.

The choice of objective tests made by family practitioners when faced with this problem appears at odds with these recommendations. Bronchoprovocation was not selected by any respondent as a test of preference and PEFR was the most commonly used measure of airway narrowing. A key reason for this appears to be the limited access to bronchoprovocation challenges in primary care. In our cohort, $85 \%$ of family practitioners have no access to any sort of bronchoprovocation testing; $11 \%$ have access to laboratory-based exercise tests while only $4 \%$ reported access to $\mathrm{EVH}$, methacholine or mannitol provocation testing. Our findings are supported by the UK TUE applications completed by family practitioners, which indicated PEFR in $28 \%$ of cases, spirometry in $3 \%$ and bronchoprovocation in $0.05 \%$ (personal communication, UK Sport). In contrast sports medicine specialists completing the TUE application provided supporting evidence of diagnosis with bronchoprovocation in $14 \%$ of cases. This may relate to differences in patient populations; however, does highlight the fact that the physicians most likely to initially encounter individuals with this condition have least access to the most accurate diagnostic tests. Furthermore, as of January 2009, the lack of access to these tests has important implications for the preparation of a medical file to fulfil the criteria for TUE and as such potentially limits the ability of family practitioners to manage competitive athletes with this problem.

The approach to an athlete with suspected EIB by family practitioners in England appears to contrast with that of family practitioners in the US [9]. On presentation of a similar case scenario, $81 \%$ of family practitioners in the US opted for empirical treatment and $18 \%$ for investigation vs. $23 \%$ and $72 \%$ respectively, in our study cohort. The practise of family practitioners in England appears more in line with US pulmonologists who were four-fold more likely than the family practitioners to employ testing initially. However, it should be noted that the US survey 
format only offered bronchoprovocation testing as means of investigation and in no instance was this method selected by responders in this study

When initiating treatment the vast majority of family practitioners in England (90\%) indicated they would initiate treatment with a SABA alone. This is in line with guideline recommendations [12] and with reports of similar therapy preference in US family practitioners [9] and Finnish doctors [15]. In the treatment of EIB in athletes it is increasingly recognised that treatment with $\beta_{2}$-agonists alone may not be adequate and has problems including tachyphylaxis and unfavourable side effects [16]. Furthermore, given the fact that there is recognised inflammatory component [17] and that athletes require medication regularly it has been recommended that early initiation of ICS is preferable [12]. In this study, $6 \%$ of family practitioners indicated they would initially treat with ICS, although this rose to $75 \%$ when faced with a re-consult at two months. Perhaps alarmingly, given the recommendations not to prescribe LABA without ICS, 3\% of family practitioners chose this treatment strategy. Interestingly, despite an 'other' option being available in the answer section, no respondents indicated alternative recognized treatment options such as a warm-up [18], avoidance of triggers [2] or dietary modification $[19,20]$. Further work is needed to determine whether this may reflect a definitive choice on the part of family practitioners or be the result of a lack of dissemination or awareness of current evidence or teaching of sport and exercise medicine in England [21].

The approach chosen by many respondents to initiate treatment empirically is confounded by the poor correlation between subjective symptoms and objective evidence of airway narrowing [7]. It also presents a number of diagnostic difficulties if an individual represents with ongoing symptoms. The PRACTALL guidelines recommended that if EIB treatment is not successful then other diagnoses should be re-considered including vocal cord dysfunction, arterial hypoxemia and general poor physical fitness [10]. However, other possibilities include: insufficient treatment; poor therapy compliance; or ineffective inhaler technique. To explore this further we represented the athlete at two months after initiation of empirical treatment. Interestingly, almost half of respondents opted to arrange investigation at this point, whilst only one third opted to change treatment.

In treating competitive athletes, the majority of respondents $(66 \%)$ indicated they were unsure which medication(s) a competitive athlete (in this scenario a cyclist) was permitted to use without notifying their governing body (Table 1). These findings are in keeping with previous surveys of family practitioners in the UK and France suggesting a limited knowledge of the implications of prescribing medication to this specialist population $[22,23]$. Although the onus remains on the athlete to inform a governing body of prohibited medication use, physicians should be aware of the process especially given the changes in the requirements for a medical file for TUE from January 2009.

Our study has a number of limitations. Firstly, similar to the report by Parsons and colleagues [9] the methods employed to distribute the survey meant that we were unable to accurately assess response rate. An electronically distributed method was selected in order to allow realistic feedback however as such did not allow us to determine delivery confirmation. To our knowledge, this study is the first to use this approach to survey family practitioners nationwide using the electronic e-mail database. We have no reason to believe bias in one direction within responses and furthermore our findings are supported by family practitioner completed TUE applications. Secondly, the wording of case scenario was selected to be suggestive of $\mathrm{EIB}$, however it is acknowledged that the differential diagnosis is broad and potentially includes other respiratory and cardiac pathologies. We therefore provided an 'other' option and correspondingly a small proportion of family practitioners selected investigations, such as chest radiographs and electrocardiographs. Finally, the methods employed only permitted a single distribution of the survey. As such the findings would be supported and further validated by repeating assessment on an additional occasion.

\section{Conclusion}

The findings from this study provide an insight into the manner in which athletes with exercise-related respiratory symptoms are diagnosed and managed in primary care. The results indicate that although some form of objective testing is often employed in diagnostic work-up, the tests most frequently employed are not the most accurate for the diagnosis of EIB.

Overall the findings have implications for the management and hence welfare of athletes presenting with exercise-related respiratory symptoms to primary care but also have important implications for competitive athletes requiring medical evidence in support of TUE application.

\section{Competing interests}

JPP has received speaking fees from Glaxosmithkline inc., Merck inc and Schering-plough inc. Other authors have no competing interests.

\section{Authors' contributions}

JHH made substantial contributions to conception and design, and the analysis and interpretation of data; was 
involved in drafting the manuscript and revising it critically for important intellectual content; and has given final approval of the version to be published. PJHmade substantial contributions to conception and design; was involved in revising the manuscript critically for important intellectual content; and has given final approval of the version to be published. JPPmade substantial contributions to the analysis and interpretation of data; was involved in revising the manuscript critically for important intellectual content; and has given final approval of the version to be published. JWDmade substantial contributions to the analysis and interpretation of data; was involved in revising the manuscript critically for important intellectual content; and has given final approval of the version to be published. LAmade substantial contributions to conception and design, and acquisition of data, and the analysis and interpretation of data; was involved in drafting the manuscript and revising it critically for important intellectual content; and has given final approval of the version to be published.

\section{Acknowledgements}

We would like to thank family practitioners who completed the survey and would also like to thank N. Wojek and M. Stow from UK Sport for providing UK TUE application data.

\section{References}

I. Dickinson JW, Whyte GP, McConnell AK, Harries MG: Impact of changes in the IOC-MC asthma criteria: a British perspective. Thorax 2005, 60:629-632.

2. Parsons JP, Mastronarde JG: Exercise-induced bronchoconstriction in athletes. Chest 2005, 128:3966-3974.

3. Hull JH, Ansley L, Garrod R, Dickinson JW: Exercise-induced bronchoconstriction in athletes-should we screen? Med Sci Sports Exerc 2007, 39:2117-2124.

4. Anderson SD, Sue-Chu M, Perry CP, Gratziou C, Kippelen P, McKenzie DC, Beck KC, Fitch KD: Bronchial challenges in athletes applying to inhale a beta2-agonist at the 2004 Summer Olympics. J Allergy Clin Immunol 2006, I I 7:767-773.

5. International standard for therapeutic use exemptions [http://www.wada-ama.org/rtecontent/document/ IST TUE En 2009.pdf]

6. Holzer $K$, Anderson $S D$, Douglass J: Exercise in elite summer athletes: Challenges for diagnosis. J Allergy Clin Immunol 2002, I 1 0:374-380.

7. Rundell KW, Im J, Mayers LB, Wilber RL, Szmedra L, Schmitz HR: Self-reported symptoms and exercise-induced asthma in the elite athlete. Med Sci Sports Exerc 200I, 33:208-2I3.

8. Anderson SD, Brusasco V, Haahtela T, Popov T: Criteria for diagnosis of asthma, EIB and AHR for athletes: lessons from the Olympic Games. In Diagnosis, Prevention and Treatment of ExerciseRelated Asthma, Respiratory and Allergic Disorders in Sport (European Respiratory Monograph) Volume 33. Edited by: Carlsen KH, Delgado L, DelGiacco S. European Respiratory Society Journals Ltd; 2005:48-66.

9. Parsons JP, O'Brien JM, Lucarelli MR, Mastronarde JG: Differences in the evaluation and management of exercise-induced bronchospasm between family physicians and pulmonologists. J Asthma 2006, 43:379-384.

10. Schwartz LB, Delgado L, Craig T, Bonini S, Carlsen KH, Casale TB, Del GS, Drobnic F, van Wijk RG, Ferrer M, et al.: Exercise-induced hypersensitivity syndromes in recreational and competitive athletes: a PRACTALL consensus report (what the general practitioner should know about sports and allergy). Allergy 2008, 63:953-96I.

II. Johansson H, Foucard T, Pettersson LG: Exercise tests in large groups of children are not a suitable screening procedure for undiagnosed asthma. Allergy 1997, 52: | I 28-I I 32.
12. Carlsen KH, Anderson SD, Bjermer L, Bonini S, Brusasco V, Canonica W, Cummiskey J, Delgado L, Del G Sr, Drobnic F, et al.: Treatment of exercise-induced asthma, respiratory and allergic disorders in sports and the relationship to doping: Part II of the report from the Joint Task Force of European Respiratory Society (ERS) and European Academy of Allergy and Clinical Immunology (EAACI) in cooperation with GA(2)LEN. Allergy 2008, 63:492-505.

13. Fitch KD, Sue-Chu M, Anderson SD, Boulet LP, Hancox RJ, McKenzie DC, Backer V, Rundell KW, Alonso JM, Kippelen P, et al.: Asthma and the elite athlete: summary of the International Olympic Committee's consensus conference, Lausanne, Switzerland, January 22-24, 2008. J Allergy Clin Immunol 2008, I 22:254-60-60.

14. Holzer K, Brukner P: Screening of athletes for exercise-induced bronchoconstriction. Clin J Sport Med 2004, I 4: I34- 138.

15. Helenius I, Haahtela T: Allergy and asthma in elite summer sport athletes. J Allergy Clin Immunol 2000, 106:444-452.

16. Anderson SD, Caillaud C, Brannan JD: Beta2-agonists and exercise-induced asthma. Clin Rev Allergy Immunol 2006, 3 I: 163-180.

17. Sue-Chu M, Larsson L, Moen T, Rennard SI, Bjermer L: Bronchoscopy and bronchoalveolar lavage findings in cross-country skiers with and without "ski asthma". Eur Respir J 1999, 13:626-632.

18. Mickleborough TD, Lindley MR, Turner LA: Comparative effects of a high-intensity interval warm-up and salbutamol on the bronchoconstrictor response to exercise in asthmatic athletes. Int J Sports Med 2007, 28:456-462.

19. Mickleborough TD, Lindley MR, Alina AI, Fly AD: Protective effect of fish oil supplementation on exercise-induced bronchoconstriction in asthma. Chest 2006, 129:39.

20. Mickleborough TD: A nutritional approach to managing exercise-induced asthma. Exerc Sport Sci Rev 2008, 36:135-144.

21. Cullen M, McNally O, Neill SO, Macauley D: Sport and exercise medicine in undergraduate medical schools in the United Kingdom and Ireland. Br J Sports Med 2000, 34:244-245.

22. Greenway P, Greenway M: General practitioner knowledge of prohibited substances in sport. Br J Sports Med I997, 31: | 29- I3I.

23. Laure $P$, Binsinger $C$, Lecerf T: General practitioners and doping in sport: attitudes and experience. Br J Sports Med 2003, 37:335-338

\section{Pre-publication history}

The pre-publication history for this paper can be accessed here:

http://www.biomedcentral.com/1471-2466/9/29/prepub

Publish with Bio Med Central and every scientist can read your work free of charge

"BioMed Central will be the most significant development for disseminating the results of biomedical research in our lifetime."

Sir Paul Nurse, Cancer Research UK

Your research papers will be:

- available free of charge to the entire biomedical community

- peer reviewed and published immediately upon acceptance

- cited in PubMed and archived on PubMed Central

- yours - you keep the copyright

Submit your manuscript here:

http://www.biomedcentral.com/info/publishing_adv.asp
BioMedcentral 